\title{
Oxygen desaturation on the six-minute walk test and mortality in untreated primary pulmonary hypertension
}

\author{
G. Paciocco*, F.J. Martinez", E. Bossone*, E. Pielsticker*, B. Gillespie*, M. Rubenfire*
}

Oxygen desaturation on the six-minute walk test and mortality in untreated primary pulmonary hypertension. G. Paciocco, F.J. Martinez, E. Bossone, E. Pielsticker, B. Gillespie, M. Rubenfire. (C) ERS Journals Ltd 2001.

ABSTRACT: There are no reliable predictors of mortality in primary pulmonary hypertension (PPH). This study assessed whether exercise oxygen desaturation and distance achieved during a six-minute walk are associated with mortality in moderately symptomatic patients with PPH.

Thirty-four patients with PPH underwent a pretreatment six-minute walk test, and an invasive haemodynamic assessment of pulmonary vasodilator reserve, to select the best treatment option (epoprostenol in 27 and nifedipine in 7). Median follow-up was 26 months (12 months for the nonsurvivors was $26 \%$ ), and median survival, $>46$ months by Kaplan-Maier estimate.

The mean \pm SD distance walked was $275 \pm 155 \mathrm{~m}$ and reduction in arterial oxygen saturation $\left(S_{\mathrm{a}}, \mathrm{O}_{2}\right)$ at maximal distance $\left(\Delta \mathrm{S}_{\mathrm{a}}, \mathrm{O}_{2}\right)$ was $8.4 \pm 4.5 \%$. A distance $\leqslant 300 \mathrm{~m}$ increased mortality risk by 2.4 , and a $\Delta S_{\mathrm{a}, \mathrm{O}_{2}}$ of $\geqslant 10 \%$ increased mortality risk by 2.9 . Only $S_{\mathrm{a}}, \mathrm{O}_{2}$ at peak distance, $\Delta \mathrm{S}_{\mathrm{a}}, \mathrm{O}_{2}$ and pulmonary vascular resistance (PVR) were related to mortality. After adjusting for PVR, there remained a $27 \%$ increase in risk of death for each per cent decrease in $\mathrm{Sa}_{\mathrm{a}} \mathrm{O}_{2}$.

The six-minute walk distance and exercise oxygen saturation may be helpful in selecting patients with primary pulmonary hypertension for whom transplant listing is appropriate.

Eur Respir J 2001; 17: 647-652.

Primary pulmonary hypertension (PPH) is characterized by a progressive increase in pulmonary vascular resistance (PVR) and a near universally fatal outcome $[1,2]$. Epoprostenol [3, 4] and oral calcium channel blocking agents [5] can improve the clinical course in $\mathrm{PPH}$, but the long-term prognosis remains relatively poor and the rate of deterioration is not readily predicted from clinical parameters. Neither symptom relief, nor initial reduction in PVR assures a good longterm prognosis [2].

In congestive heart failure [6, 7] and chronic pulmonary diseases $[8,9]$ the six-minute walk test has gained increasing acceptance as a simple tool to assess functional capacity. Furthermore, the level of desaturation during the walk correlates with the degree of impairment of both heart and lung function [10, 11]. A prospective study was therefore designed to determine whether the distanced walked and/or the arterial oxygen desaturation on a pretreatment six-minute walk test is associated with an increase in mortality in moderately symptomatic PPH.

\section{Methods}

\section{Study population}

Fifty-four patients diagnosed with PPH 1992-1997 in the University of Michigan Pulmonary Hypertension
*Dept of Internal Medicine, Division of Cardiology, "Division of Pulmonary and Critical Care Medicine and Centre for Biostatistics, University of Michigan, Ann Arbor, MI, USA.

Correspondence: M. Rubenfire University of Michigan 24 Frank Lloyd Wright Drive 48106, Ann Arbor, MI USA Fax: 017349987456

Keywords: Mortality oximetry pulmonary hypertension

Received: January 122000 Accepted after revision October 262000
Center were evaluated. PPH was defined by a mean pulmonary artery pressure (mPAP) $>25 \mathrm{mmHg}$ after exclusion of secondary causes such as pulmonary embolus, collagen vascular disease, sleep apnoea, lung disease, and congenital, valvular, or other heart disease, with the exception of atrial septal defect without left to right shunt [12]. One patient had portal-pulmonary hypertension. Seventeen patients were excluded for the following reasons: previous treatment with calcium channel blockers or intravenous (i.v.) epoprostenol, and New York Heart Association (NYHA) class IV or orthopaedic issues precluding the walk. Patients with pulmonary veno-occlusive disease or human immunodeficiency virus were also excluded.

The thirty-four eligible patients underwent a detailed examination, pulmonary function testing, and a standardized six-minute test with monitoring of arterial oxygen saturation $\left(\mathrm{Sa}_{\mathrm{a}} \mathrm{O}_{2}\right)$. Right heart catheterization with assessment of pulmonary vasodilator reserve was used to determine the best treatment strategy in all patients. Pulmonary vasodilator reserve was determined by the response to $5 \mathrm{~min}$ inhaled nitric oxide ( 80 parts per million) (as described by Ricciardi et al. [13]) in 24 subjects, incremental doses of intravenous adenosine (as described by SCHRADER et al. [14]) in 6 subjects, and incremental doses of short acting nifedipine (as described by Rich et al. [15]) in seven subjects. Patients with pulmonary vasodilator reserve, defined as a decrease in mPAP and/or PVR by $\geqslant 20 \%$ 
with inhaled nitric oxide or $i . v$. adenosine, underwent a subsequent trial of short acting nifedipine [13]. Those with pulmonary vasodilator reserve following short acting nifedipine were placed on sustained release nifedipine, and the remaining were treated with continuous i.v. epoprostenol.

Seven patients were treated with nifedipine only. In 23 patients the initial treatment was intravenous epoprostenol, and in four epoprostenol was utilized following deterioration on high dose nifedipine (nifedipine was discontinued). One patient died shortly after a double lung transplant. The mean \pm sD dose of nifedipine was $220 \pm 92 \mathrm{mg}$. Epoprostenol was administered via an indwelling Hickman catheter, initially titrated to symptom tolerance without hypotension. The usual starting dose was 4-6 $\mathrm{ng} \cdot \mathrm{kg}^{-1} \cdot \mathrm{min}^{-1}$. The dose was adjusted regularly with the mean dosage increased by $1-2 \mathrm{ng} \cdot \mathrm{kg}^{-1} \cdot \mathrm{min}^{-1}$, every 2 weeks for the first 6 months, then monthly according to symptoms and side effects. Patients were encouraged to tolerate common side effects such as jaw claudication and flushing.

Standard treatment included digoxin (levels measured at three month intervals) and sodium warfarin, adjusted to an international normalized ratio of 2-3 with nifedipine and 1.5-2 with epoprostenol. Diuretics (furosemide and spironolactone) were used to control oedema and ascites. Patients $<60$ yrs of age were referred for lung transplant.

\section{Pulmonary function}

Pulmonary function tests were measured with a 1070 Hans Rudolf pneumotachograph (Medical Graphics Co, St. Paul, MN, USA) and corrected for temperature and barometric pressure [16]. Arterial blood gases were drawn from the radial artery on room-air prior to the pulmonary function and six-minute walk tests, and measured by standard gas analysis (Radiometer, ABL 520, Radiometer America Inc., Westlake, OH, USA).

\section{The six-minute walk test and arterial pulse oximetry}

The six-minute walk was administered a minimum of $2 \mathrm{~h}$ after the pulmonary function test by a certified technician, unaware of the results, using a protocol similar to that of ScIURBA et al. [9]. Briefly, the patients walked on a level circular surface with a length of $42 \mathrm{~m}$, with standardized instructions including to walk as quickly and comfortably possible for $6 \mathrm{~min}$ without running, and gently encouraged using set phrases every 30 seconds [7, 9, 17].

Cutaneous $\mathrm{Sa}_{2} \mathrm{O}_{2}$ was assessed at baseline and during the walk by a continuous pulse oximeter (Nellcor N3000, Mallinckrodt Inc., Hazelwood, MO, USA) using the finger or ear. The test was stopped for safety purposes if the $S \mathrm{a}, \mathrm{O}_{2}$ dropped $<86 \%$ with the exception of patients with an atrial level right to left shunt [18]. The walk was repeated with oxygen supplementation in those with resting or exercise $\mathrm{S}_{\mathrm{a}, \mathrm{O}_{2}}<90 \%$ to determine the need and dosage for supplemental oxygen.

The baseline arterial oxygen saturation ( $\mathrm{Sa}, \mathrm{O}_{2}$-rest), the minimal exercise arterial oxygen saturation sustained for $>10 \mathrm{~s}\left(\mathrm{~S}_{\mathrm{a}}, \mathrm{O}_{2}\right.$-exercise), the change (decrease) during the walk $\left(\mathrm{Sa}_{\mathrm{a}} \mathrm{O}_{2}\right.$-rest $-\mathrm{Sa}_{\mathrm{a}} \mathrm{O}_{2}$-exercise $\left.=\Delta \mathrm{S}_{\mathrm{a}}, \mathrm{O}_{2}\right)$ and the distance walked were recorded and calculated.

\section{Haemodynamic assessment}

Right heart catheterization was performed via the internal jugular or femoral vein in the fasting state. A four-lumen (additional lumen for stiffening wire) balloon flotation catheter was used for thermodilution cardiac output (CO), and sampling of mixed venous oxygen saturation and pressures. Brachial artery pressure was measured by an automated noninvasive cuff using Doppler signals, or via the radial or femoral artery when systolic pressure was $<100 \mathrm{mmHg}$. Mean pressures were derived electronically. The following haemodynamic parameters were measured and/or calculated: systolic, diastolic, and mean pulmonary artery pressures and right atrial pressure (sPAP, dPAP, mPAP, and mRAP, respectively), $\mathrm{CO}$, pulmonary capillary wedge (PCW) and PVR (mPAP-PCW)/CO) in Wood units.

\section{Statistical methods}

Continuous variables are presented as mean \pm sD, and counts and percentages given for categorical variables. Categorical comparisons were performed by Chisquared and continuous data by unpaired t-tests. The statistical significance level was set at $\mathrm{p}<0.05$.

Survival analysis was used to analyse the time to death data from the time of initial diagnosis. The survival distribution was estimated using the KaplanMeier estimator with censoring of transplanted cases at time of lung transplant. The effects of covariates on survival time were tested using Cox regression. Because there were only nine deaths, one variable at a time was entered in the Cox model. Hazard ratios, the incremental risk or odds of death attributable to having versus not having a parameter, and corresponding confidence intervals, were computed. For continuous variables, hazard ratios are expressed in terms of meaningful units of measurement. The median followup time was estimated using the Kaplan-Meier method with censoring as the endpoint and deaths and time of lung transplant considered censored values.

\section{Results}

\section{Demographic and clinical parameters}

Twenty-eight of the 34 patients were female. The mean age was $44.3 \pm 11.9$ yrs (range $23-67$ yrs). There was no age or sex difference between survivors and nonsurvivors. Seven were NYHA class II at baseline (2 nonsurvivors) and 27 NYHA class III (7 nonsurvivors). The mean time from initial symptoms to diagnosis was $17.8 \pm 13$ months (median 12 months, range $1-60$ months). The commonest symptom was dyspnoea on exertion (94\%). Most patients had other symptoms 
Table 1. - Baseline haemodynamic parameters by survival and New York Heart Association (NYHA) class

\begin{tabular}{|c|c|c|c|c|c|}
\hline \multirow[b]{2}{*}{ Haemodynamic parameters } & \multicolumn{3}{|c|}{ Survival status } & \multicolumn{2}{|c|}{ NYHA class } \\
\hline & All patients & Nonsurvivors & Survivors & NYHA II & NYHA III \\
\hline Subjects $\mathrm{n}$ & 34 & 9 & 25 & 7 & 27 \\
\hline mRAP mean $\mathrm{mmHg}$ & $13 \pm 6$ & $14 \pm 5$ & $11 \pm 6$ & $11 \pm 6$ & $12 \pm 6$ \\
\hline sPAP systolic $\mathrm{mmHg}$ & $89 \pm 14$ & $89 \pm 14$ & $89 \pm 14$ & $82 \pm 13$ & $91 \pm 14$ \\
\hline dPAP diastolic $\mathrm{mmHg}$ & $39 \pm 9$ & $44 \pm 11$ & $38 \pm 8$ & $38 \pm 9$ & $40 \pm 9$ \\
\hline mPAP mean $\mathrm{mmHg}$ & $56 \pm 10$ & $59 \pm 12$ & $55 \pm 9$ & $53 \pm 9$ & $57 \pm 10$ \\
\hline PCW mmHg & $13 \pm 4$ & $13 \pm 5$ & $13 \pm 4$ & $12 \pm 3$ & $13 \pm 4$ \\
\hline $\mathrm{CO} \mathrm{L} \cdot \mathrm{min}^{-1}$ & $3.9 \pm 1.5$ & $3.4 \pm 1.6^{* *}$ & $4 \pm 1.5$ & $3.5 \pm 0.7$ & $4.0 \pm 1.7$ \\
\hline PVR Wood units & $12.9 \pm 5.3$ & $15.5 \pm 6.0^{*}$ & $11.9 \pm 4.7$ & $12.0 \pm 3.5$ & $13.1 \pm 5.7$ \\
\hline
\end{tabular}

Data are presented as mean \pm SD. mRAP: mean right atrial pressure; sPAP: systolic pulmonary artery pressure; dPAP: diastolic pulmonary artery pressure; mPAP: mean pulmonary artery pressure; PCW: capillary wedge pressure; CO: cardiac output; PVR: pulmonary vascular resistance; *: $\mathrm{p}=0.05$, PVR nonsurvivors versus survivors; **: $\mathrm{p}=0.11$, CO nonsurvivors versus survivors.

including fatigue $(21 \%)$, light-headedness $(24 \%)$, palpitations $(24 \%)$, oedema $(18 \%)$, syncope $(15 \%)$ and chest pain $(6 \%)$.

Haemodynamic, pulmonary function, and blood gas parameters

The initial baseline haemodynamic parameters are summarized and displayed by NYHA class and survivors versus nonsurvivors in table 1 . The mRAP was $12.5 \pm 6.3 \mathrm{mmHg}$, mPAP $56.9 \pm 12.1 \mathrm{mmHg}, \mathrm{CO} 3.9 \pm 1.5$ $\mathrm{L} \cdot \mathrm{min}^{-1}$, and PVR 12.9 \pm 5.3 Wood units. There was no statistical difference in haemodynamic parameters between survivors and nonsurvivors or between NYHA class II and class III, with the exception of PVR, which was higher in nonsurvivors $(15.5 \pm 6.0$ Wood units versus 11.9 \pm 4.7 Wood units, $p=0.04$ ).

The pulmonary function tests were normal in 55\% of patients. Thirty two per cent of patients had a restrictive pattern, $13 \%$ an obstructive pattern, and carbon monoxide diffusion capacity $(D \mathrm{~L}, \mathrm{CO})$ was $<70 \%$ in $45 \%$ of patients. There was no sex difference in pulmonary function abnormalities. The majority of patients had one or more abnormalities in resting blood gases. Seventy-seven per cent of the patients were hypoxaemic $\left(\mathrm{PO}_{2}<70 \mathrm{mmHg}\right), 59 \%$ hypocapnic $\left(P_{C}<35 \mathrm{mmHg}\right)$, and respiratory alkalosis $(\mathrm{pH}$ $>7.44$ ) was present in $56 \%$ of patients. The mean $\mathrm{Sa}, \mathrm{O}_{2}$ determined from the arterial $\mathrm{PO}_{2}$ after correcting for $\mathrm{pH}$ was $91.7 \pm 4.2 \%$.
Exercise oximetry and distance on the six-minute walk test

The oximetry and distances walked are summarized in table 2 and presented by NYHA class and survival. The peak distance walked was $275 \pm 155 \mathrm{~m}$, less in males than females $(183 \pm 80 \mathrm{~m}$ versus $290 \pm 160 \mathrm{~m}, \mathrm{p}<0.05)$, and greater in NYHA class II than NYHA class III ( $352 \pm 196 \mathrm{~m}$ versus $255 \pm 141 \mathrm{~m}, \mathrm{p}=0.05$ ).

Only ten patients $(29 \%)$ walked for the $6 \mathrm{~min}$. Twenty-four $(71 \%)$ were stopped due to an $\mathrm{Sa}_{2} \mathrm{O}_{2}-$ exercise $\leqslant 86 \%$. The $\mathrm{Sa}_{\mathrm{a}} \mathrm{O}_{2}$-rest was $<94 \%$ in eight patients $(23.5 \%)$ with a mean of $94.8 \pm 4.7 \%$, and at peak distance decreased below normal (decrease $>4 \%$ ) in 27 patients $(79 \%)$. The mean $\mathrm{Sa}_{\mathrm{a}} \mathrm{O}_{2}$-exercise was $87.4 \pm 7.1 \%$, a decrease of $8.5 \pm 4.5 \%$, which was worse in males than females (males $=11.5 \pm 6.2 \%$ versus females $=$ $7.8 \pm 4.0 \%, \mathrm{p}=0.03$ ). The eighteen patients who desaturated by $<10 \%$ achieved a peak distance of $<300 \mathrm{~m}$, and $78 \%$ of them had no intracardiac shunt by contrast echo-Doppler.

\section{Description of nonsurvivors}

Two deaths occurred during the first year and seven during the second yr following diagnosis. In the nine nonsurvivors, treatment was epoprostenol in six; epoprostenol after nifedipine failure in two, and nifedipine in one. Two deaths occurred despite atrial septostomy and extra corporal membrane oxygenation

Table 2. - Results of the six-minute walk test and distribution of oxygen desaturation by survival and New York Heart Association (NYHA) class

\begin{tabular}{|c|c|c|c|c|c|}
\hline & \multirow{2}{*}{ Total } & \multicolumn{2}{|c|}{ Survival status } & \multicolumn{2}{|c|}{ NYHA class } \\
\hline & & Survivors & Nonsurvivors & NYHA II & NYHA III \\
\hline Subjects $\mathrm{n}$ & 34 & 25 & 9 & 7 & 27 \\
\hline $1-4 \%$ desat & $8(24)$ & $8(32)$ & $0(0)$ & $2(29)$ & $6(22)$ \\
\hline $5-9 \%$ desat & $8(24)$ & $7(28)$ & $1(11)$ & $2(29)$ & $6(22)$ \\
\hline$\geqslant 10 \%$ desat & $18(53)$ & $10(40)$ & $8(89)$ & $3(43)$ & $15(56)$ \\
\hline \multicolumn{6}{|l|}{ Distance walked m } \\
\hline$<300$ & $23(68)$ & $15(60)$ & $8(89)$ & $3(43)$ & $20(74)$ \\
\hline $300-600$ & $11(32)$ & $10(40)$ & $1(11)$ & $4(57)$ & $7(26)$ \\
\hline
\end{tabular}

Data are presented as $\mathrm{n}\left(\%\right.$ of total patients). desat: reduction in $\mathrm{Sa}_{\mathrm{a}} \mathrm{O}_{2}$. 


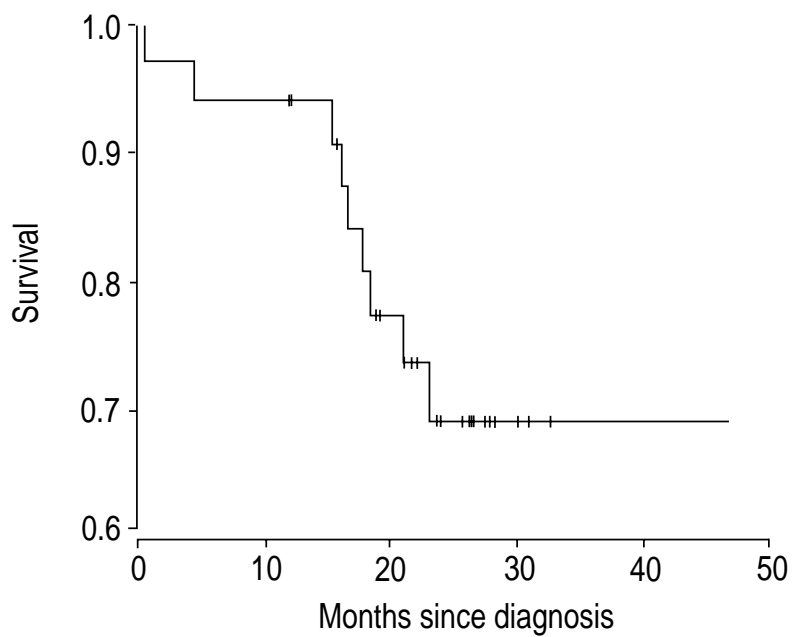

Fig. 1. - Kaplan-Meier estimate of the survival function by months since diagnosis. Censored values $(+)$ indicate the last known follow-up time for those patients still alive and transplanted.

(ECMO) support, and one following a double lung transplant.

\section{Survival results}

Twenty-five $(74 \%)$ were considered survivors at the time of analysis. The median follow-up time was 26 months (12 months for deceased and 46 months for survivors). Figure 1 is the Kaplan-Meier estimate of survival function in months from diagnosis. The 25th percentile of survival time was 21 months, with a median survival of $>46$ months.

The variables entered into the Cox model, to identify those related to survival time, are presented in table 3 . The only significant variables were $\mathrm{Sa}_{\mathrm{a}} \mathrm{O}_{2}$-exercise, the decrease in $S \mathrm{a}, \mathrm{O}_{2}$-exercise $\left(\Delta \mathrm{S}_{\mathrm{a}}, \mathrm{O}_{2}\right)$ and PVR. There was a $26 \%$ increase in risk of death for each percent decrease in oxygen saturation, $\mathrm{p}=0.02$. The significance of $\Delta \mathrm{S}_{\mathrm{a}, \mathrm{O}_{2}}$ was not diminished after adjustment for haemodynamic variables (mRAP, mPAP, CO, PVR) or NYHA class. After adjustment for PVR, the effect of $\Delta \mathrm{Sa}_{\mathrm{a}} \mathrm{O}_{2}$ was essentially unchanged. There was a $16 \%$ increase in risk of death for each Wood unit increase in PVR $(\mathrm{p}=0.04)$. After adjusting for $\Delta S_{\mathrm{a}}, \mathrm{O}_{2}$, the effect of PVR was slightly diminished $(\mathrm{p}=0.06)$.

The total distance walked was associated with a better prognosis. An 18\% reduction in risk of death occurred with each $50 \mathrm{~m}$ increase in distance $(\mathrm{p}=0.11)$. After adjusting for $\Delta \mathrm{Sa}_{\mathrm{a}, \mathrm{O}_{2}}$ in the Cox regression, distance walked was not associated with death $(\mathrm{p}=0.3)$, but after adjusting for distance walked the $\Delta S \mathrm{a}, \mathrm{O}_{2}$ remained significant $(\mathrm{p}<0.05)$. There was no significant relationship between slow vital capacity (SVC), forced vital capacity (FVC), the ratio of forced expiratory volume in one second to forced vital capacity (FEV1/ FVC), DL,CO, or arterial pH, $\mathrm{PCO}_{2}$, or $\mathrm{PO}_{2}$ and mortality.

The presence of an intra-atrial right to left shunt (2 atrial septal defects and 4 patent foramen ovale) was not associated with death, and the increase in mortality associated with increasing exercise oxygen desaturation remained after adjusting for possible intracardiac shunting $(\mathrm{p}=0.056)$. Mortality also remained elevated after adjustment for NYHA class III, but the population size was insufficient to determine the relationship between $\mathrm{Sa}_{\mathrm{a}} \mathrm{O}_{2}$-exercise and mortality in NYHA class II.

\section{Discussion}

It was hypothesized that the degree of arterial desaturation and distance achieved on a standardized six-minute walk test would complement other clinical and haemodynamic parameters for identifying patients at risk of death in PPH. In this study of 34

Table 3. - Results of Cox regression analysis relating survival time to individual selected variables

\begin{tabular}{|c|c|c|}
\hline Variable & Hazard ratio $(95 \% \mathrm{CI})$ & p-value \\
\hline NYHA class & $0.60(0.11-3.20)$ & 0.55 \\
\hline VC L & $0.97(0.93-1.00)$ & 0.22 \\
\hline FVC L & $0.99(0.95-1.03)$ & 0.51 \\
\hline FEV1 L & $0.98(0.94-1.03)$ & 0.47 \\
\hline$D \mathrm{~L}, \mathrm{CO} \mathrm{mL} \cdot \mathrm{min}^{-1} \cdot \mathrm{mmHg}^{-1}$ & $0.99(0.93-1.05)$ & 0.74 \\
\hline Arterial $\mathrm{PO}_{2} \mathrm{mmHg}$ & $0.97(0.91-1.03)$ & 0.28 \\
\hline Arterial $\mathrm{PCO}_{2} \mathrm{mmHg}$ & $0.86(0.74-1.01)$ & 0.07 \\
\hline Arterial $\mathrm{pH}$ & $1.28(0.93-1.76)$ (per 0.01 increase in $\mathrm{pH}$ value) & 0.13 \\
\hline $\mathrm{Sa}_{\mathrm{a}} \mathrm{O}_{2}$-rest $\%$ & $0.91(0.81-1.01)$ & 0.09 \\
\hline $\mathrm{Sa}_{\mathrm{a}, \mathrm{O}_{2}}$-exercise $\%$ & $0.92(0.85-0.99)$ & 0.03 \\
\hline$\Delta S_{\mathrm{a}}, \mathrm{O}_{2} \%$ & $1.26(1.04-1.53)$ (per each $1 \%$ decrease) & 0.02 \\
\hline Distance $\mathrm{m}$ & $0.82(0.63-1.05)$ (per 50 meters increase in distance) & 0.11 \\
\hline mRAP $\mathrm{mmHg}$ & $1.09(0.95-1.24)$ & 0.19 \\
\hline mPAP $\mathrm{mmHg}$ & $1.23(1.03-1.47)$ & 0.33 \\
\hline $\mathrm{CO} \mathrm{L} \cdot \mathrm{min}^{-1}$ & $0.66(0.38-1.14)$ & 0.14 \\
\hline PVR Wood units & $1.12(1.01-1.26)$ & 0.04 \\
\hline
\end{tabular}

NYHA: New York Heart Association; VC: slow vital capacity; FVC: forced vital capacity; FEV1: forced expired volume in the first second; $D \mathrm{~L}, \mathrm{CO}$ : diffusing capacity for carbon monoxide; $\mathrm{PO}_{2}$ : arterial oxygen tension; $\mathrm{PCO}_{2}$ : arterial carbon dioxide tension; $S_{\mathrm{a}}, \mathrm{O}_{2}$-rest: oxygen saturation at rest; $\mathrm{Sa}_{\mathrm{a}} \mathrm{O}_{2}$-exercise: trough of oxygen saturation during six-minute walk test; $\Delta S_{\mathrm{a}}, \mathrm{O}_{2}$ : difference between resting and trough oxygen saturation; mRAP: mean right atrial pressure; mPAP: mean pulmonary artery pressure; CO: cardiac output; PVR: pulmonary vascular resistance. 
patients with PPH, of whom 27 were treated with epoprostenol, the mortality was $26.5 \%$ and all deaths occurred within the 2 yrs of diagnosis. The lone clinical, pulmonary, and haemodynamic parameters associated with survival time were the decrease in $\mathrm{Sa}_{2} \mathrm{O}_{2}$ with exercise and PVR. There was a $26 \%$ increase in risk of death for each per cent decrease in $\mathrm{Sa}_{\mathrm{a}} \mathrm{O}_{2}$. The decrease or change in $\mathrm{Sa}, \mathrm{O}_{2}$ between rest and peak-exercise time (mean $\Delta \mathrm{Sa}_{\mathrm{a}} \mathrm{O}_{2}$ of $8.65 \pm 4.55 \%$ ) was comparable to patients with moderately severe chronic obstructive pulmonary disease [6] Further, exercise arterial desaturation remained significant after adjustment for distance and haemodynamic parameters. The results are particularly striking, since NYHA class IV patients were included.

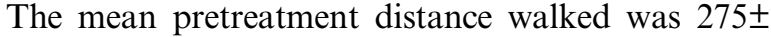
$155 \mathrm{~m}$, comparable to previous reports $[4,19,20]$. As in the study of KADIKAR et al. [19], a trend, but no significant relationship was found, between decreasing distance walked pretreatment and risk of mortality. In contrast, in patients tested on treatment ( 38 of 43 on prostacyclin derivatives) Мгунотото et al. [20] found a distance of $<332 \mathrm{~m}$ on the six-minute walk test was associated with decrease in survival. That the ontreatment but not pretreatment distance walked would correlate with outcome is consistent with the improved prognosis attributable to prostacyclin. It is possible the pretreatment distance would correlate better with mortality in a larger cohort of patients than the present study.

In the United States National Institutes of Health PPH registry, which included NYHA class IV subjects, there was a correlation between reduced FVC and decreased DL,CO and poor survival [1]. The present authors could not identify a significant correlation between any spirometric variable and survival time, suggesting that when abnormal, these parameters are reflective of adverse haemodynamic indices. The reduction in DL,CO found in $45 \%$ of patients in this study is consistent with the obliteration of small pulmonary arteries and low cardiac output.

\section{Implications of findings}

The median survival time following diagnosis in the PPH National Institutes of Health Registry was 2.8 yrs [1]. Epoprostenol and treatment based upon invasive haemodynamic parameters and pulmonary vasodilator reserve are major advances in the management of a nearly uniformly fatal disease. However, a group remains with an unfavourable response to treatment for whom transplantation is the only viable option [1, 21, 22]. Therapeutic decisions are complicated by the inaccuracy of risk predictors, which have not been validated in the epoprostenol era $[1,22,23]$. Considering the present findings, the clinical assessment of PPH patients for listing for transplant should include both the oxygen desaturation and distance achieved on the six-minute walk test [19].

\section{Limitations of this study}

While the size of this study is limited, that each patient was cared for with a standardized protocol by a multidisciplinary team in an experienced regional centre lends strength to the observations. The patients are typical of PPH in the US regarding clinical, pulmonary, and haemodynamic parameters, and available treatment options. Eligible patients were listed for lung transplant, but as elsewhere, the regional time for receiving a lung during the study period was over 18 months and precluded this option in eight of the nine deaths.

Methods used for the six-minute walk test vary, but the one employed in this series is similar to recent recommendations $[9,18]$. The standardized protocol requires three sessions to obtain optimal reproducibility [9], but the need to begin treatment precluded us from retesting. To reduce the impact of test variability, patients were educated with a short introductory walk and rested for $\geqslant 1 \mathrm{~h}$. Importantly, while experience could impact the distance walked, it would have no influence on the degree of desaturation, which was the major significant outcome variable.

The present data suggest that a pretreatment sixminute walk test may be a useful adjunct in the functional evaluation of patients with primary pulmonary hypertension. The utility of arterial oxygen desaturation is independent of New York Heart Association (class II and III) and remains significant after correction for haemodynamic parameters. If the current findings can be validated in a larger multi-institutional cohort, more accurate and appropriate risk stratification and selection of patients for lung or heart-lung transplant in primary pulmonary hypertension will become feasible.

\section{References}

1. D'Alonzo GE, Barst RJ, Ayres SM, et al. Survival in patients with primary pulmonary hypertension. Results from a national prospective registry. Ann Intern Med 1991; 115: 343-349.

2. Rubin LJ. Primary pulmonary hypertension. $N$ Engl $J$ Med 1997; 336: 111-117.

3. Rubin LJ, Mendoza J, Hood M, et al. Treatment of primary pulmonary hypertension with continuous intravenous prostacyclin (epoprostenol). Results of a randomized trial. Ann Intern Med 1990; 112: 485-491.

4. Barst RJ, Rubin LJ, McGoon MD, Caldwell EJ, Long WA, Levy PS. Survival in primary pulmonary hypertension with long-term continuous intravenous prostacyclin. Ann Intern Med 1994; 121: 409-415.

5. Rich S, Kaufmann E, Levy PS. The effect of high doses of calcium-channel blockers on survival in primary pulmonary hypertension. N Engl J Med 1992; 327: 7681.

6. Guyatt GH, Thompson PJ, Berman LB, et al. How should we measure function in patients with chronic heart and lung disease? J Chronic Dis 1985; 38: $517-$ 524.

7. Guyatt GH, Sullivan MJ, Thompson PJ, et al. The 6minute walk: a new measure of exercise capacity in patients with chronic heart failure. Can Med Assoc J. 1985; 132: 919-923.

8. Steel B. Timed walking tests of exercise capacity in chronic cardiopulmonary illness. J Cardiopulmonary Rehab 1996; 16: 251-257. 
9. Sciurba F, Slivka W. Six-minute walk testing. Semin Resp and Crit Care Med 1998; 19: 383-392.

10. Cahalin LP, Mathier MA, Semigran MJ, Dec GW, DiSalvo TG. The six-minute walk test predicts peak oxygen uptake and survival in patients with advanced heart failure. Chest 1996; 110: 325-332.

11. Efthimiou J, Mounsey PJ, Benson DN, Madgwick R, Coles SJ, Benson MK. Effect of carbohydrate rich versus fat rich loads on gas exchange and walking performance in patients with chronic obstructive lung disease. Thorax 1992; 4: 451-456.

12. Rich S, Dantzker DR, Ayres SM, et al. Primary pulmonary hypertension. A national prospective study. Ann Intern Med 1987; 107: 216-223.

13. Ricciardi MJ, Knight BP, Martinez FJ, Rubenfire M. Inhaled nitric oxide in primary pulmonary hypertension: a safe and effective agent for predicting response to nifedipine. J Am Coll Cardiol 1998; 32: 1068-1073.

14. Schrader BJ, Inbar S, Kaufmann L, Vestal RE, Rich S. Comparison of the effects of adenosine and nifedipine in pulmonary hypertension. J Am Coll Cardiol 1992; 19: 1060-1064.

15. Rich S, Kaufmann E. High dose titration of calcium channel blocking agents for primary pulmonary hypertension: guidelines for short-term drug testing. J Am Coll Cardiol 1991; 18: 1323-1327.

16. Crapo RO. Pulmonary-function testing. $N$ Engl J Med 1994; 331: 25-30.
17. Guyatt GH, Pugsley SO, Sullivan MJ, et al. Effect of encouragement on walking test performance. Thorax 1984; 39: 818-822.

18. Foss C. Pulse Oximetry with Exercise: Assessment of Desaturation, Oxygen Titration and Distance Walked. In: Wanger J, ed. Pulmonary Function and Laboratory Management and Procedural Manual: American Thoracic Society; 1998.

19. Kadikar A, Maurer J, Kesten S. The six-minute walk test: a guide to assessment for lung transplantation. $J$ Heart Lung Transplant 1997; 16: 313-319.

20. Miyamoto $\mathrm{S}$, Nagaya $\mathrm{N}$, Satoh $\mathrm{T}$, et al. Clinical correlates and prognostic significance of six-minute walk test in patients with primary pulmonary hypertension. Comparison with cardiopulmonary exercise testing. Am J Respir Crit Care Med 2000; 161: 487492.

21. Barst RJ, Rubin LJ, Long WA, et al. A comparison of continuous intravenous epoprostenol (prostacyclin) with conventional therapy for primary pulmonary hypertension. The Primary Pulmonary Hypertension Study Group. N Engl J Med 1996; 334: 296-302.

22. Sandoval J, Bauerle O, Palomar A, et al. Survival in primary pulmonary hypertension. Validation of a prognostic equation. Circulation 1994; 89: 1733-1744.

23. Nootens M, Freels S, Kaufmann E, Levy PS, Rich S. Timing of single lung transplantation for primary pulmonary hypertension. J Heart Lung Transplant 1994; 13: 276-281. 